\title{
PENGARUH PENDIDIKAN KARAKTER TERHADAP PEMAHAMAN KARIR SISWA KELAS VIII SMP NEGERI 1 KWALA BEGUMIT KABUPATEN LANGKAT TAHUN AJARAN 2018/2019
}

\author{
Julkifli, M.Pd ${ }^{1}$ \\ M. Dian Wahyudi, M.Pd ${ }^{2}$ \\ STKIP Budidaya Binjai ${ }^{1,2}$
}

\begin{abstract}
ABSTRAK
Pendidikan karakter merupakan sesuatu yang mengualifikasi seorang pribadi, keadaan jiwa yang menyebabkan seseorang bertindak tanpa difikirkan terlebih dahulu, keadaan atau kondisi jiwa yang bersifat batiniah, sifat alami seseorang dalam merespons situasi secara bermoral, cara berfikir dan berperilaku yang menjadi ciri khas setiap individu untuk hidup dan bekerjasama, baik dalam lingkungan keluarga, masyarakat, bangsa dan negara. Karir bagi siswa bukan hal yang mudah untuk ditentukan dan menjadi pilihan yang sesuai dengan kemampuan yang miliki namun haruslah ditentukan. Untuk membentukan hal demikian harus didasarkan pada keputusan siswa itu sendiri yang didasarkan pada pemahaman tentang kemampuan dan minat serta pengenalan karir yang ada di masyarakat. Keberhasilan siswa dalam pemilihan karir yang tepat tidaklah semudah seperti apa yang dibayangkan, agar siswa mempunyai pilihan yang tepat terhadap suatu pilihan karir atau pekerjaan. pendidikan karakter diperuntukkan semua siswa agar siswa mampu mengembangkan karakternya dengan baik dan berlandaskan kebijakan-kebijakan inti yang secara objektif baik bagi individu maupun masyarakat, serta telah dilaksanakan dan dinilai sangat baik. Pendidikan karakter di SMP Negeri 1 Kwula Begumit setelah dilakukan Penelitian memberikan pengaruh terhadap pemahaman karir siswa sebesar 88,08\% yang tidak berpengaruh sebesar 11,92\%.Pemahaman karir siswa kelas VIII SMP Negeri 1 Kwala Begumit Kecamatan Binjai tergolong sedang dengan persentase $77,61 \%$, berarti pemahaman karir sebesar 22,49\% perlu ditingkatkan oleh pihak sekolah dalam hal ini petugas bimbingan dan konselinglah yang dimaksud. Terdapat hubungan positif yang sangat signifikan antara pendidikan karakter terhadap pemahaman karir siswa. Hasil ini di buktikan dengan koefisien korelasi $r_{x y}=0,993$ dan telah dikorelasikan dengan $r_{\text {tabel }}$ pada taraf signifikansi 5\% ternyata $r_{\text {hitung }}$ lebih besar dari $r_{\text {tabel }}(0,993>0,304)$. Dengan demikian, maka dapat dinyatakan bahwa pendidikan karakter di sekolah dilakukan sesuai dengan ketentuan akan berpengaruh terhadap pemahaman karir siswa. Sebaliknya, bila pendidikan karakter di sekolah tidak sesuai dengan ketentuan maka pemahaman karir siswa di sekolah tidak berhasil.
\end{abstract}

Kata Kunci : Pendidikan Karakter dan Pemahaman Karir Siswa 


\section{PENDAHULUAN}

Bekerja merupakan suatu bidang yang sangat penting dalam mengisi waktu kehidupan orang dewasa yang menuntut pemikiran dan menyentuh sebahagian besar perasaan. Melalui pekerjaan seseorang melayani keperluan masyarakat, mendapat imbalan untuk memenuhi ekonomi, menciptakan identitas diri dan menumbuhkan rasa harga diri. Selain itu jabatan yang di pegang seseorang ikut menentukan pula kehidupan sehari-hari dan pergaulan sosial. Gaya hidup seseorang dipengaruhi oleh jabatannya, termasuk kegiatannya dalam waktu senggang sebagai kelanjutan dari jabatannya atau sebagai kompenssi terhadap kekurangan yang dirasakan dalam lingkup jabatannya.

Makna pekerjaan dan jabatan dalam kehidupan orang dewasa semakin tampak, bila mana dia tidak memperoleh kepuasaan pribadi dari pekerjaannya disebabkan berbagai kendala yang melekat pada dirinya sendiri atau tumpukan hambatan yang terdapat dalam lingkungan pekerjaannya. Orang merasa tidak bahagia dan bercampur dengan rasa frustasi yang akhirnya dapat mengancam kesehatan mentalnya.

Kemampuan dan kesempurnaan yang diberikan Tuhan kepada manusia tidak akan dapat berkembang secara optimal tanpa adanya suatu kerja keras. Kerja keras tersebut harus sesuai dengan potensi yang dimiliki oleh manusia. Potensi yang ada pada diri manusia perlu digali dan dikembangkan menjadi sebuah prestasi yang membanggakan. Potensi diri tidak akan terlihat tanpa adanya prestasi. Potensi dapat diartikan sebagai kemampuan dasar dari sesuatu yang masih terpendam didalamnya yang menunggu untuk diwujudkan menjadi suatu kekuatan nyata dalam diri sesuatu tersebut. Dengan demikian potensi diri manusia adalah kemampuan dasar yang dimiliki manusia yang masih terpendam di dalam diriya yang menunggu untuk diwujudkan menjadi suatu manfaat yang nyata dalam kehidupan diri manusia.

Satu hal yang sudah terbukti dan sering dilihat dilingkungan sekitar kita bahwa biasanya kesempatan sangat cepat diraih oleh orang-orang yang memahami potensi dirinya secara baik.

Dalam Undang-Undang No. 20 tahun 2003 pasal 3 mengenai Sistem Pendidikan Nasional dinyatakan bahwa "Pendidikan nasional bertujuan untuk berkembangnya potensi peserta didik agar menjadi manusia yang beriman dan bertaqwa kepada Tuhan Yang Maha Esa, berakhlak mulia, sehat, berilmu, cakap, kreatif, mandiri, dan menjadi warga Negara yang demokratis serta bertanggung jawab. Jadi, secara jelas Undang-Undang Sistem Pendidikan Nasional Indonesia menyebutkan pengembangan berbagai karakter sebagai tujuannya, seperti beriman, bertaqwa, berakhlak mulia, kreatif, mandiri, dan menjadi warga Negara yang demokratis dan bertanggung jawab".

Sejalan dengan Undang-Undang di atas pada pasal 1 menyebutkan "Pendidikan adalah usaha sadar dan terencana untuk mewujudkan suasana belajar dan proses pembelajaran agar peserta didik secara aktif mengembangkan potensi dirinya untuk memiliki kepribadian, kecerdasan, serta 
keterampilan yang diperlukan dirinya, masyarakat, bangsa dan Negara".

Pembentukan karakter merupakan salah satu tujuan pendidikan nasional adalah mengembangkan potensi peserta didik untuk memiliki kecerdasan, kepribadian, dan akhlak mulia. Pesan dalam UU pada pasal 1 di atsa ini, pendidikan tidak hanya membentuk insan Indonesia yang cerdas, namun juga berkepribadian atau berkarakter. Tapi sayangnya pelaksanaan itu kurang terlaksana dengan baik. Sehingga banyak anak sekolah yang karakternya masih kurang baik. Semoga saja, apabila pengajar dan orang tua mengajar anak dengan baik, akan membuat karakter anak menjadi lebih baik pula.

Mengingat pentingnya masalah karir dalam kehidupan manusia, sejak dini anak perlu dipersiapkan dan dibantu untuk merencanakan hari depan yang lebih cerah, dengan cara memberikan pendidikan dan bimbingan karir yang berkelanjutan. Oleh karena itu, layanan bimbingan dan konseling merupakan kegiatan yang terencana berdasarkan pengukuran kebutuhan yang diwujudkan dalam bentuk program bimbingan dan konseling. Program bimbingan dan konseling ini dapat menjadi landasan yang jelas terukur oleh layanan profesional yang diberikan oleh konselor disekolah. Dalam hal ini pendidikan karakter lebih ditekankan untuk mengatasi permasalahan karir siswa.

Menurunnya karakter siswa di sekolah perlu dibenahi agar dimasa mendatang siswa memiliki akhlak, nilai dan moral yang lebih baik dari sekarang. Dalam hal ini guru pembimbing sangat diperlukan untuk membantu siswa dalam pemahaman pemilihan karirnya melalui pendidikan karakter. Pendidikan karakter merupakan pendidikan nilai, yakni pendidikan nilai-nilai luhur yang bersumber dari budaya bangsa sendiri, dalam membina kepribadian generasi muda. membina kepribadian generasi muda dimaksudkan agar siswa dapat memahami dan memilih karimya sesuai dengan potensi, minat dan bakat yang dimiliki siswa.

Berdasarkan hasil observasi yang penulis lakukan saat PPLI (Program Pengalaman Lapangan Integratif) masih banyak orang-orang yang kurang memahami potensi yang ada pada diri mereka termasuk siswa-siswi yang belajar di suatu lembaga pendidikan. Orang yang belum mengenali potensi dirinya sering kali merasa ragu apakah diri mereka cocok menekuni satu bidang tertentu. Memahami potensi diri sangat penting karena merupakan titik tolak pertama dalam menuju pencapaian langkah cita-cita.

\section{METODOLOGI PENELITIAN}

Adapun metode penelitian yang digunakan dalam penelitian ini adalah penelitian Kuantitaitf, dalam penelitian ini peneliti ingin mengatahui sebarapa besar pengaruh Pendidikan Karakter terhadap Pemahaman Karir Siswa.

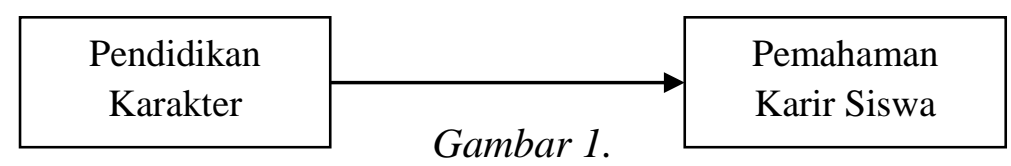

Kerangka Penelitian 
2018/2019. Kegiatan penelitian direncanakan dimulai pada bulan Februari 2018 dan berakhir pada bulan Mei 2018.

\section{TEMPAT PENELITIAN}

\section{POPULASI DAN SAMPEL}

\section{Populasi}

Populasi dalam penelitian ini adalah seluruh siswa kelas VIII Negeri 1 Kwala Begumit Kecamatan Binjai Kabupaten Langkat yang dapat dilihat pada tabel diatas.

Tabel 1. Populasi Jumlah Siswa/Siswi Kelas VIII SMP Negeri 1 Kwala Begumit Kecamatan Binjai Tahun Pelajaran 2018/2019.

\begin{tabular}{ccccc}
\hline $\begin{array}{c}\text { N } \\
\mathbf{o}\end{array}$ & Kelas & Pr & Lk & $\begin{array}{c}\text { Jumlah } \\
\text { Siswa }\end{array}$ \\
\hline 1. & VIII-a & 22 & 18 & 40 \\
& & Orang & Orang & Orang \\
\hline 2. & VIII-b & 24 & 16 & 40 \\
& & Orang & Orang & Orang \\
\hline 3. & VIII-c & 19 & 20 & 39 \\
& & Orang & Orang & Orang \\
\hline 4. & VIII-d & 25 & 15 & 40 \\
& & Orang & Orang & Orang \\
\hline 5. & VIII-e & 28 & 12 & 40 \\
& & Orang & Orang & Orang \\
\hline 6. & VIII-f & 16 & 25 & 41 \\
& & Orang & Orang & Orang \\
\hline 7. & VIII-g & 22 & 17 & 39 \\
& & Orang & Orang & Orang \\
\hline & Jumlah & $\mathbf{1 5 7}$ & $\mathbf{1 2 3}$ & $\mathbf{2 7 9}$ \\
& & & & Orang \\
\hline
\end{tabular}

\section{Sampel}

Sampel penelitian dalam penelitian ini berjumlah 42 orang atau $15 \%$ dari jumlah
Lokasi dari penelitian ini adalah SMP Negeri 1 Kwala Begumit Kecamatan Binjai yang beralokasi di jalan S. Parman Desa Kwala Begumit Kecamatan Binjai kabupaten Langkat.

populasi secara keseluruhan. Untuk lebih jelasnya deskripsi sampel dalam penelitian ini seperti tertera pada tabel dibawah ini :

Tabel 2. Deskripsi Sampel Penelitian

\begin{tabular}{cccc}
\hline No & Kelas & $\begin{array}{c}\text { Jumlah } \\
\text { Siswa }\end{array}$ & Jumlah Sampel \\
\hline 1 & VIII-a & 40 & $15 \%$ dari $40=6$ \\
& & Orang & Orang \\
\hline 2 & VIII-b & 40 & $15 \%$ dari $40=6$ \\
& & Orang & Orang \\
\hline 3 & VIII-c & 39 & 15\% dari 39 $=6$ \\
& & Orang & Orang \\
\hline 4 & VIII-d & 40 & $15 \%$ dari $40=6$ \\
& & Orang & Orang \\
\hline 5 & VIII-e & 40 & $15 \%$ dari 40 $=6$ \\
& & Orang & Orang \\
\hline 6 & VIII-f & 41 & $15 \%$ dari 41 $=6$ \\
& & Orang & Orang \\
\hline 7 & VIII-g & 39 & $15 \%$ dari 39=6 \\
& & Orang & Orang \\
\hline \multirow{4}{*}{ Jumlah } & $\mathbf{2 7 9}$ & $\mathbf{4 2 ~ O r a n g}$ \\
& & Orang & \\
\hline
\end{tabular}

\section{TEKNIK PENGUMPULAN DATA}

Teknik Pengumpulan Data dalam penelitian ini dengan Menggunakan angket dan wawancara.

\section{TEKNIK ANALISIS DATA}

Menganalisis data merupakan salah satu cara yang digunakan untuk mengolah data 
penelitian guna memperoleh suatu kesimpulan. Teknik analisa data yang digunakan dalam penelitian ini adalah Analisa Korelasi Product Moment dari Karl Pearson. Teknik analisa ini digunakan untuk melihat pengaruh antara satu variabel bebas dengan satu variabel terikat. Variabel bebas dalam penelitian ini adalah pendidikan karakter dan yang menjadi variabel terikatnya adalah pemahaman karir siswa.

Dalam penelitian ini analisis data yang digunakan adalah:

\section{Uji Homogenitas}

Uji homogenitas data yang digunakan untuk melihat apakah ada kedua kelompok sampel mempunyai varians yang homogen atau tidak, untuk itu dilakukan uji $\mathrm{F}$ yaitu dengan menggunakan rumus sebagai berikut:

$F \frac{V_{b}}{V_{k}}$, dimana: $\mathrm{V}_{\mathrm{b}}=$ varians terbesar

$$
\mathrm{V}_{\mathrm{k}}=\text { varians terkecil }
$$

Kriteria pengujian hipotesis:

Jika $F_{\text {hitung }}>F_{\text {tabel }}$, maka kedua sampel tidak mempunyai varians yang sama.

Jika $F_{\text {hitung }}<F_{\text {tabel }}$, maka kedua sampel

mempunyai varians yang sama.

\section{Uji Asosiatif (Pengaruh)}

Untuk mengetahui seberapa besar pengaruh antara pendidikan karakter dan pemahaman karir siswa dengan menggunakan analisis korelasi. Adapun rumus Analisis Korelasi Product Moment dari Karl Pearson adalah sebagai berikut :

$$
r_{x y}=\frac{\sum X Y}{\sqrt{\sum x^{2} \sum y^{2}}}
$$

Keterangan :

$\mathrm{r}_{\mathrm{xy}} \quad=$ Koefisien korelasi antara variabel $\mathrm{X}$ (pemahaman karir)

$$
\text { dengan variabel Y (pendidikan }
$$

karakter) $\sum X Y=$ Jumlah hasil perkalian antara variabel $X$ dan $Y$

$\sum X \quad=$ Jumlah skor keseluruhan subjek variabel bebas $X$

$\sum Y \quad=$ Jumlah skor keseluruhan subjek variabel $\mathrm{Y}$

$\sum X^{2}=$ Jumlah kuadrat skor variabel $\mathrm{X}$

$\sum Y^{2}=$ Jumlah kuadrat skor variabel $\mathrm{Y}$

$\mathrm{N} \quad=$ Jumlah subjek

Setelah nilai $r$ diketahui, maka peneliti menguji signifikan korelasi product moment digunakan uji t-tabel, dengan rumus sebagai berikut:

Keterangan:

$$
t=\frac{r \sqrt{n-2}}{\sqrt{1-r^{2}}}
$$

$\mathrm{t}$ : Signifikan korelasi

$r$ : Koefisien korelasi

$\mathrm{n}$ : Jumlah sampel

\section{PEMBAHASAN}

\section{Deskrifsi Data}

\section{a. Data Pendidikan Karakter (Variabel X)}

Data hasil angket pendidikan karakter, di kelas VIII SMP Negeri 1 Kwala Begumit Kecamatan Binjai Tahun Pelajaran 2018/2019 sebanyak 42 siswa dengan jumlah 10 item. Jumlah total skor angket $\mathrm{X}$ (variable bebas) = 1284, dengan skor tertinggi 36 dan skor terendah 25.

Dari analisis data pendidikan karakter diperoleh:
a. Skor tertinggi $=36$
b. Skor terendah $=25$
c. Rentangan $=\mathrm{R}=36-25=11$ 
$\mathrm{BK}=1+3,3 \log \mathrm{n}$ (rumus sturgess)

$$
=1+3,3 \log 42=1+3,3
$$

$(1,62)=1+5,346=6,346=7$

d. Menentukan panjang kelas (i)

$$
i=\frac{R}{B K}=\frac{11}{7}=1,57=2
$$

Panjang interval kelas diambil sebesar 2.

Berikut tabel distribusi frekuensinya:

Tabel 3. Distribusi Frekuensi Pendidikan

\begin{tabular}{|c|c|c|c|c|c|c|}
\hline No & $\begin{array}{l}\text { Kelas } \\
\text { Interval }\end{array}$ & $\mathrm{F}$ & $\mathrm{Xi}$ & $\mathrm{Xi}^{2}$ & fXi & $f X i^{2}$ \\
\hline 1 & $25-26$ & 4 & 25,5 & 650,25 & 102 & 10404 \\
\hline 2 & $27-28$ & 6 & 27,5 & 756,25 & 165 & 27225 \\
\hline 3 & $29-30$ & 6 & 29.5 & 870,25 & 177 & 31329 \\
\hline 4 & $31-32$ & 16 & 31,5 & 992,25 & 504 & 254016 \\
\hline 5 & $33-34$ & 8 & 33,5 & 1122,25 & 268 & 71824 \\
\hline 6 & $35-36$ & 2 & 35,5 & 1260,25 & 71 & 5041 \\
\hline 7 & & $\begin{array}{l}N \\
= \\
42\end{array}$ & 183 & 5651,5 & 1287 & 399839 \\
\hline
\end{tabular}

Karakter

Modus untuk frekuensi pendidikan karakter adalah 16

Batas kelas modus Bb $1 / 2=(31+32)=31,5$

Panjang kelas modus $\mathrm{P}=32$ sampai $33=1$

$\mathrm{F}_{1}=\mathrm{f}-\mathrm{f}_{\mathrm{sb}}=16-6=10$

$\mathrm{F}_{2}=\mathrm{f}_{\text {sd }}=16-8=8$

Maka modus pendidikan karakter adalah : Mo

$=\mathrm{Bb}+\mathrm{P}\left[\frac{F 1}{F 1+F 2}\right]$

$\mathrm{Mo}=31,5+1\left[\frac{10}{10+8}\right]=31,5+1\left[\frac{10}{18}\right]=31,5+$

$[0,555]=32,055$

Berikut diagram histogram data pendidikan karakter:

Gambar 1. Diagram Histogram

Tentang Data Pendidikan Karakter

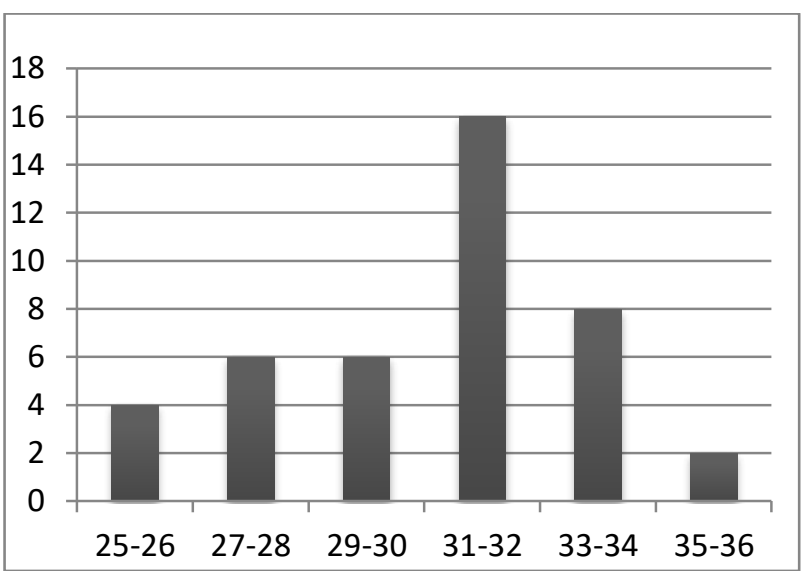

\section{b. Data Penmahaman Karir (Variabel Y)}

Data hasil angket pemahaman karir, di kelas VIII SMP Negeri 1 Kwala Begumit Kecamatan Binjai Tahun Pelajaran 2018/2019 sebanyak 42 siswa dengan jumlah 10 item. Jumlah total skor angket $X$ (variabel terikat) = 1387, dengan skor tertinggi 39 dan skor terendah 26.

Dari analisis data pemahaman karir diperoleh:

a. Skor tertinggi $=39$

b. Skor terendah $=26$

c. Rentangan $=R=39-26=14$

$\mathrm{BK}=1+3,3 \log \mathrm{n}$ (rumus sturgess)

$$
=1+3,3 \log 42(1,62)=1
$$

$+5,346=6,346=7$

d. Menentukan panjang kelas (i)

$i=\frac{R}{B K}=\frac{14}{7}=2$

Panjang interval kelas diambil sebesar 2.

Berikut tabel distribusi frekuensinya:

Tabel 4. Distribusi Frekuensi Pemahaman Karir

\begin{tabular}{|c|c|c|c|c|c|c|}
\hline No & $\begin{array}{c}\text { Kelas } \\
\text { Interval }\end{array}$ & $\mathrm{F}$ & $\mathrm{Xi}$ & $\mathrm{Xi}^{2}$ & $\mathrm{fXi}$ & $\mathrm{fXi}^{2}$ \\
\hline 1 & $26-27$ & 7 & 26,5 & 702,25 & 159 & 25281 \\
\hline 2 & $28-29$ & 6 & 28,5 & 812,25 & 274,5 & 75350,25 \\
\hline 3 & $30-31$ & 0 & 30.5 & 930,25 & 30,5 & 930,25 \\
\hline
\end{tabular}




\begin{tabular}{|c|c|c|c|c|c|c|}
\hline 4 & $32-33$ & 6 & 32,5 & 1056,25 & 455 & 207025 \\
\hline 5 & $34-35$ & 9 & 34,5 & 1190,25 & 69 & 4761 \\
\hline 6 & $36-37$ & 4 & 36,5 & 1332,25 & 73 & 5329 \\
\hline 7 & $38-39$ & 10 & 38,5 & 1482,25 & 385 & 14822,5 \\
\hline 7 & & $\begin{array}{c}\mathrm{N} \\
= \\
42\end{array}$ & 189 & 6173,5 & 1274,5 & 377282,25 \\
& & & & \\
\hline
\end{tabular}

$$
\begin{gathered}
\mathrm{F}_{\text {hitung }}=\frac{S 1^{2}}{S 2^{2}} \\
\text { Kriteria pengujian, terima } \mathrm{H} 0 \\
\text { jika } \mathrm{F}_{\text {hitung }}>\mathrm{F}_{\text {tabel }} \\
\mathrm{F}_{\text {hitung }}=\frac{v_{b}}{v_{k}} \\
\mathrm{~F}_{\text {hitung }}=\frac{32,055}{32,875}=0,97
\end{gathered}
$$

Gambar 2. Diagram Histogram

Tentang Data Pemahaman Karir

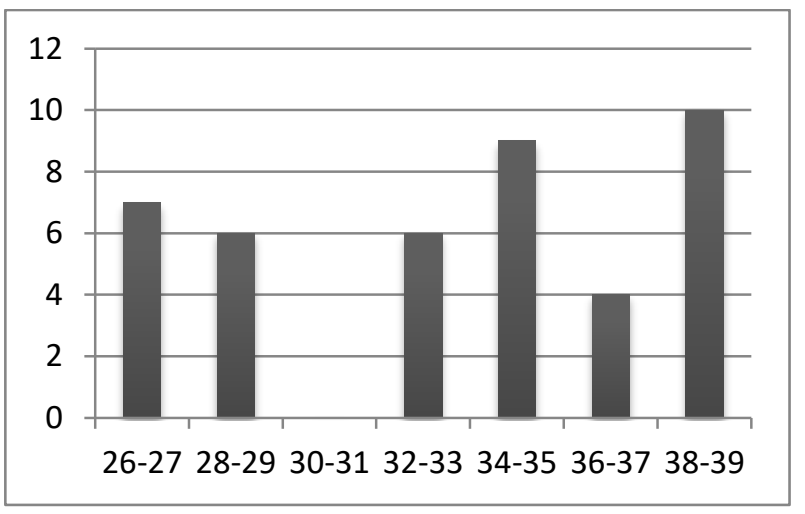

Modus untuk frekuensi bimbingan dan

konseling adalah 9

Batas kelas modus Bb $1 / 2=(32+33)=32,5$

Panjang kelas modus $\mathrm{P}=32$ sampai $33=1$

$\mathrm{F}_{1}=\mathrm{f}-\mathrm{f}_{\mathrm{sb}}=9-6=3$

$\mathrm{F}_{2}=\mathrm{f}_{\mathrm{sd}}=9-4=5$

Maka modus pemahaman karir adalah : Mo =

$\mathrm{Bb}+\mathrm{P}\left[\frac{F 1}{F 1+F 2}\right]$

$\mathrm{Mo}=32,5+1\left[\frac{3}{3+5}\right]=32,5+1\left[\frac{3}{8}\right]=32,5+$

$[0,375]=32,875$

Selanjutnya mencari pengujian analisis data menggunakan uji homogenitas dan uji asosiatif sebagai berikut:

\section{Uji Homogenitas Varians Data Penelitian}

Untuk menguji apakah kedua kelompok homogen, akan diuji hipotesis sebagai berikut: Ha : $\alpha 1^{2}=\alpha 2^{2}$ $\mathrm{H} 0: \alpha 1^{2} \neq \alpha 2^{2}$

Rumus yang digunakan adalah:
Dari perhitungan di atas diperoleh $F_{\text {hitung }}$ $=0,97$ dan dari grafik daftar distribusi $F$ dengan $\mathrm{dk}$ pembilang $=42-1=41$, dan $\mathrm{dk}$ penyebut $=42-1=41$ dan $\alpha=0,05$ dan $\mathrm{F}_{\text {tabel }}=$ 1,69 Tampak bahwa $F_{\text {hitung }}<\mathrm{F}_{\text {tabel, }}$ maka disimpulkan bahwa variabel data $\mathrm{X}$ dan $\mathrm{Y}$ homogen.

\section{HIPOTESIS}

Untuk mengetahui ada tidaknya pengaruh antara variabel $\mathrm{X}$ dan variabel $\mathrm{Y}$ maka dilakukan pengujian dengan rumus Korelasi Product Moment.

$\begin{array}{lll}\sum X Y & = & 42650 \\ \sum X & = & 1284 \\ \sum Y & = & 1387 \\ \sum X^{2} & = & 39528 \\ \sum Y^{2} & = & 46615 \\ \mathrm{~N} & = & 42\end{array}$

Selanjutnya dimasukkan kerumus Korelasi

Product Moment sebagai berikut:

$$
\begin{aligned}
& r_{x y}=\frac{\sum X Y}{\sqrt{\sum x^{2} \sum y^{2}}} \\
& r_{x y}=\frac{42650}{\sqrt{(39528)(46615)}} \\
& r_{x y}=\frac{42650}{\sqrt{1842597720}} \\
& r_{x y}=\frac{42650}{42925,49} \\
& r_{x y}=0,993
\end{aligned}
$$

Setelah nilai $\mathrm{r}$ diketahui, maka perlu diketahui tentang erat tidaknya hubungan/pengaruh (korelasi) antara pendidikan karakter dengan pemahaman karir 
siswa kelas VIII SMP Negeri 1 Kwala Begumit Kecamatan Binjai Tahun Pelajaran 2013/2014. Dalam pengujian hipotesis yang diuji adalah koefisien korelasinya $\left(\mathrm{r}_{\mathrm{xy}}\right)=0,993$ (Sangat Baik). Koefisien korelasi ini dikonsultasikan diinterpretasikan dengan $r_{\text {tabel }}$ dan taraf nyata $\alpha$ $=0,05$.

Kriteria pengujian : Terima Ha jika $r_{x y}<r_{\text {tabel }}$ Tolak H0 jika $r_{x y}>r_{\text {tabel }}$

Selanjutnya harga $r$ hitung tersebut dibandingkan dengan harga $\mathrm{r}_{\text {tabel, dan untuk }}$ taraf signifikan 5\% dan $\mathrm{N}=42$, maka $\mathrm{r}$ tabel $=$ 0,304, sedangkan $r$ hitung $=0,993$, hal tersebut dapat disimpulkan bahwa $r_{\text {hitung }}>r_{\text {tabel }}(0,993$ $>0,304)$. Dengan demikian hipotesis diterima, berarti ada hubungan antara variabel $\mathrm{X}$ dengan variabel Y. Untuk mengetahui signifikan tidaknya kedua hubungan antara variabel $\mathrm{X}$ dan Y maka dilakukan pengujian dengan uji hipotesis sebagai berikut:

$=\frac{r \sqrt{n-2}}{\sqrt{1-r^{2}}}$

$=\frac{0,993 \sqrt{42-2}}{\sqrt{1-0,993^{2}}}$

$=\frac{0,993 \times 6,324}{\sqrt{1-0,986}}$

$=\frac{0,993 \times 6,324}{\sqrt{0,014}}$

$=\frac{6,279}{0,118}=53,21$

Berdasarkan perhitungan hasil dari $\mathrm{t}_{\text {hitung }}=53,21$ dengan taraf signifikan nyata $\alpha=$ 0,05 dan dk yaitu $n-2=42-2=40$. Kemudian Ha diterima jika $t_{\text {hitung }}>t_{\text {tabel }}$, dan selanjutnya berdasarkan daftar $t_{\text {tabel }}=2,021$. Jadi dapat dilihat bahwa 53,21 > 2,021. Maka hipotesis ini dapat diterima. Yaitu Ha: Terdapat pengaruh yang signifikan antara pendidikan karakter terhadap pemahaman karir siswa kelas VIII SMP Negeri 1 Kwala Begumit Kecamatan Binjai Tahun Pelajaran 2018/2019.

\section{PEMBAHASAN PENELITIAN}

Setelah peneliti selesai mengolah semua data melalui tabulasi data, maka berikut ini penulis akan menganalisis data sebagai berikut:

1. Bahwa pendidikan karakter berpengaruh terhadap pemahaman karir siswa.

2. Bahwa pendidikan karakter dipengaruhi oleh peran aktif seorang konselor sekolah.

3. Selain daripada itu proses belajar mengajar akan berlangsung dengan baik jika siswasiswanya paham tentang karir.

4. Agar siswa paham tentang karir, maka diperlukan kerjasama yang terpadu antara guru bidang studi, konselor sekolah dan orang tua siswa, siswa dengan siswa, dan kerjasama antara anggota masyarakat.

\section{PENUTUP}

\section{Kesimpulan}

Berdasarkan pengajuan hipotesis dan hasil analisis data maka dalam bab ini akan disampaikan kesimpulan hasil penelitian. Adapun kesimpulannya adalah terdapat Pengaruh dari Pendidikan Karakter terhadap Pemahaman Karir Siswa Kelas VIII SMP Negeri 1 Kwala Begumit Kecamatan Binjai Tahun Pelajaran 2018/2019.

1. Bahwa pendidikan karakter diperuntukkan semua siswa agar siswa mampu mengembangkan karakternya dengan baik dan berlandaskan kebijakan-kebijakan inti yang secara objektif baik bagi individu maupun masyarakat, serta telah dilaksanakan dan dinilai sangat baik. Pendidikan karakter memberikan pengaruh terhadap pemahaman karir siswa sebesar 
$88,08 \%$ yang tidak berpengaruh sebesar $11,92 \%$.

2. Pemahaman karir siswa kelas VIII SMP Negeri 1 Kwala Begumit Kecamatan Binjai tergolong sedang dengan persentase $77,61 \%$, berarti pemahaman karir sebesar $22,49 \%$ perlu ditingkatkan oleh pihak sekolah dalam hal ini petugas bimbingan dan konselinglah yang dimaksud.

3. Terdapat hubungan positif yang sangat signifikan antara pendidikan karakter terhadap pemahaman karir siswa. Hasil ini di buktikan dengan koefisien korelasi $r_{x y}=$ 0,993 dan telah dikorelasikan dengan $r_{\text {tabel }}$ pada taraf signifikansi $5 \%$ ternyata $r_{\text {hitung }}$ lebih besar dari $r_{\text {tabel }}(0,993>0,304)$. Dengan demikian, maka dapat dinyatakan bahwa pendidikan karakter di sekolah dilakukan sesuai dengan ketentuan akan berpengaruh terhadap pemahaman karir siswa. Sebaliknya, bila pendidikan karakter di sekolah tidak sesuai dengan ketentuan maka pemahaman karir siswa di sekolah tidak berhasil. Berdasarkan hasil penelitian ini, maka hipotesis yang diajukan dinyatakan di terima. Kemudian Ha diterima jika $\mathrm{t}_{\text {hitung }}>\mathrm{t}_{\text {tabel }}$ yakni 53,21 > 2,021 maka hipotesis diterima.

\section{SARAN}

Sejalan dengan kesimpulan yang telah dibuat, maka berikut ini dapat diberikan beberapa saran, antara lain:

1. Saran kepala sekolah

Melihat kondisi pendidikan karakter yang di nilai sangat baik, maka disarankan kepada pihak sekolah agar terus berupaya mempertahankan mutu pendidikan karakter yang selama ini berlangsung di sekolah. Diharapkan dengan dinilai baiknya pendidikan karakter ini, maka para siswa lebih meningkatkan lagi pendidikan karakter di sekolah. Serta siswa juga dapat memahami akan pentingnya karirnya kelak.

\section{Saran kepada guru pembimbing}

Kepada subjek penelitian diharapkan agar lebih dapat memaksimalkan pendidikan karakter di sekolah serta dapat menggunakan fasilitas-fasilitas yang sudah disediakan oleh sekolah agar tidak menjadi sia-sia. Agar para siswa nyaman dan menjadikan guru pembimbing sebagai pengganti orang tuanya. Dengan demikian para siswa dapat belajar dengan tenang. Serta lebih menekankan pendidikan tentang karir siswa agar siswa menjadi lebih produktif dalam menentukan karirnya.

\section{Saran kepada guru bidang studi}

Disarankan kepada guru bidang studi agar dapat bekerja sesuai dengan guru pembimbing untuk dapat melaksanakan tugas sesuai dengan yang sudah ditetapkan oleh sekolah sehingga guru bimbingan dan konseling dapat melakukan tugasnya dengan baik.

\section{DAFTAR PUSTAKA}

Arifin.blogspot.com/2012/05/11-prinsippendidikan-karakter-di-sekolah-html, diakses 11 Mei 2012.

Arikunto, Suharsimi. Prosedur Penelitian Suatu Pendekatan Praktik. Jakarta, Rineka Cipta, 2010.

Sulistiawati, Belajar Psikologi (belajar Psikologi.com/pengertian-pendidikankarakter-html), diakses 01 Agustus 2012. 
Dani

We,

Defenisi

Karir

(ekonomi.kompasiana.com/manajeme $\mathrm{n} / 2013 / 07 / 06 /$ defenisi-karir378941.html), diakses 06 Juli 2013.

Dormatio.blogspot.com/2012/11/pengertiankarir.html, diakses 30 November 2012.

Muhammad Noer, Pendidikan Karakter (www. muhammadnoer.com/2012/09/pendidi kan-karakter-htlm), diakses 06 Januari 2012.

Narwanti, Sri. Pendidikan Karakter. Yogyakarta, Familia, 2011.

Prasetyo, Bambang \& Miftahul Jannah, Lina. Metode Penelitian Kuantitatif. Jakarta: Rajagrafindo, 2010.

Salahuddin, Anas. Bimbingan dan Konseling. Bandung, Pustaka Setia, 2010.

Santoso, Ananda, Kamus Lengkap Bahasa Indonesia. Surabaya, Duta Media, 2010.

Saptono. Dimensi-Dimensi Pendidikan Karakter Wawasan, Strategi, dan
Langkah Praktis. Yogyakarta, Pustaka Pelajar, 2012.

Sugiyono. Statistika untuk Penelitian. Bandung, Alfabeta, 2011.

Sulistiono. T, Pengertian Pendidikan Nasional (www.blogspot-pen-nas-html) diunggah tanggal 24 Mei 2012.

Suprapto, Peranan Konselor dalam Pendidikan Karakter (http://mgpmgl.blogdetik.co $\underline{\mathrm{m}}$ ), diakses 17 Agustus 2012.

Tim Pakar Yayasan Jati Diri Bangsa. Pendidikan Karakter Di Sekolah dari Gagasan ke Tindakan. Jakarta, Elex Media Komputerindo, 2011.

Undang-undang R.I. Nomor 20 Tahun 2003 tentang SINDIKNAS \& Peraturan Pemerintah R.I. Tahun 2010 tentang Penyelenggaraan Pendidikan serta Wajib Belajar.

Wibowo, Agus. Pendidikan Karakter Strategi Membangun Karakter Bangsa Berperadaban. Jakarta, Erlangga, 2011.

Wina, Faktor-Faktor yang Mempengaruhi Pembentukan Karakter, (http://myblogwinop31.blogspot.com/) , diakses 06 Januari 2012. 